\title{
Formación de docentes y defensa de los derechos humanos mediante actividades educativas en museari.com
}

Ricard Huerta (Universitat de València) ${ }^{a}$

aRicard Huerta es profesor de Educación Artística en el Departamento de Didáctica de la Expresión Musical, Plástica y Corporal de la Facultat de Magisteri de la Universitat de València. Miembro del Institut de Creativitat i Innovacions Educatives y del grupo CREARI de Investigación en Pedagogías Culturales (ref. GIUV2013-103). ricard.huerta@uv.es

\begin{abstract}
In the training curriculum of teachers there is a gap in important issues such as the defense of Human Rights and specifically the rights of LGBT minorities. Permanent and present issues such as homophobic bullying or reflection on sexual diversity remain invisible in the subjects of university courses for future teachers (Preliminary Education and Primary School). It is necessary to address such issues. In this paper we present an educational experience in which the students are encouraged to participate in educational activities for an online museum. Museari Museu de l'Imaginari was created to promote collaborative actions to visualize the problems of LGBT groups, encouraging the participation of artists and educators. By raising the educational activity for Museari we encourage the students to develop an educational proposal through the use of ICT. The degree of motivation has been high. The results are now available to teachers through the web $w w w$.museari.com, where free downloadable activities are generated for students and teachers.
\end{abstract}

Keywords: Teacher Training, Competencies, Art, Education, Museum, Human Rights, Didactics, ICT

\footnotetext{
Resumen

Existe un vacio curricular en la formación de docentes en lo referido a cuestiones tan importantes como la defensa de los derechos humanos y concretamente de los derechos de las minorias LGTB. Aspectos candentes y de permanente actualidad como el bullying homofóbico o la reflexión sobre la diversidad sexual permanecen prácticamente invisibilizados en las asignaturas de las carreras universitarias de Magisterio (grados de Maestro/a de Educación Infantil y Primaria). Conscientes de la necesidad de abordar dichas temáticas, presentamos una experiencia docente en la que se anima al alumnado a participar con actividades didácticas en un museo online. Museari se creó con la intención de favorecer acciones colaborativas para visibilizar la problemática de los colectivos LGTB, fomentando la participación de artistas y educadores. Al plantear las actividades didácticas para Museari animamos al alumnado a desarrollar una propuesta educativa mediante el uso de las TIC. El grado de motivación ha sido alto, y los resultados están ahora
} 
al alcance del profesorado a través de la web www.museari.com donde se pueden descargar de forma gratuita las actividades generadas.

Palabras clave: formación del profesorado, competencias, arte, educación, museo, derechos humanos, didáctica, TIC

\section{Formación de docentes y defensa de los derechos humanos mediante actividades educativas en museari.com}

\section{Introducción}

Los estudios del grado de Magisterio cuentan con dos titulaciones, la de Maestro/a Especialista en Educación Infantil y la de Maestro/a Especialista en Educación Primaria. Durante los cuatro cursos de formación universitaria para maestros y maestras concentramos mucha información en las materias cuatrimestrales, mediante asignaturas que cubren la mayoría del currículum en la preparación inicial de docentes. En los últimos años se han incrementado las asignaturas compartidas entre profesorado de varias áreas de conocimiento, un sistema que ha enriquecido la colaboración entre investigadores universitarios. A pesar del progresivo incremento de la interdeisciplinariedad, sigue resultando insuficiente la preparación del alumnado en lo referido a experiencia artística. La necesidad de formar al profesorado en cultura visual requiere un tiempo del que no disponemos. Transmitir una idea de las artes visuales como elemento de transformación social supone asumir la importancia de la imagen en tanto que fuente de conocimiento, y de fomento de la ciudadanía crítica. En la Facultat de Magisteri de la Universitat de València se han incorporado recientemente talleres formativos sobre cuestiones LGTB (siglas referidas a colectivos y movimientos de lesbianas, gays, transexuales y bisexuales), actividades que son impartidas por voluntariado de organizaciones como Lambda. Debido a mi condición de profesor especializado en educación artística, y consciente de la importancia de educar en el derecho a la diversidad, durante el curso 2015-2016 he incorporado en las asignaturas que imparto una propuesta de actividad destinada a elaborar materiales que sirvan para reflexionar sobre cuestiones candentes como el bullying homofóbico o la defensa de los derechos humanos. En este trabajo se recogen algunos de los logros conseguidos, tanto durante el proceso como en los resultados finales del proyecto.

\section{Objetivos}

En las materias de educación artística del grado de Maestro/a de Educación Primaria trabajamos con la metodología por proyectos. En asignaturas concretas que están vinculadas a menciones del grado de Primaria desde la mención en Arte y Humanidades o la mención en TIC, como puedan ser la asignatura "Educación y TIC" o la asignatura "Propuestas Didácticas en Educación Artística" (ambas cuatrimestrales), se organiza el periodo lectivo en función de cinco proyectos. En cada uno de estos proyectos se parte de una idea o concepto.

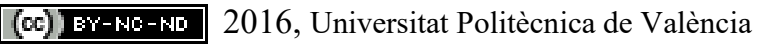


Se alternan los proyectos individuales con los proyectos que se realizan en grupo. El proyecto del cual nace la propuesta que ahora presentamos es un trabajo individual. Cada alumno o alumna presenta los resultados a toda la clase tras desarrollar su actividad durante tres semanas.

Hemos titulado la propuesta como "Proyecto Tolerancia Cero con el Bullying Homofóbico". Los objetivos que perseguimos con este proyecto son los siguientes:

- Introducir la temática de la defensa de los derechos humanos en las clases de formación inicial de maestros y maestras.

- Incorporar las cuestiones relativas a las personas y colectivos LGTB en el curriculum de formación para maestros y maestras.

- Visibilizar las problemáticas sociales y personales de los colectivos LGTBIQ (las dos últimas siglas corresponden a intersexual y queer).

- Analizar en clase las imágenes que identifican la realidad LGTBIQ.

- Concienciar al alumnado de Magisterio de la importancia de tratar estas cuestiones con la máxima normalidad.

- Comentar y reflexionar sobre el tema del bullying, revisando hasta qué punto resulta necesario atajar este grave problema en los entornos educativos.

- Revisar lo que se ha hecho hasta ahora en los ámbitos legal y educativo.

- Explicar las peculiaridades de cada caso que pueda darse en los colectivos LGTB en países donde incluso se llega a castigar con la pena de muerte.

- Hablar abiertamente de conceptos menos conocidos como la cisexualidad o la intersexualidad.

- Asumir el reto de eliminar la homofobia y la transfobia de los entornos educativos.

- Eliminar los preconceptos absurdos que suelen predominar respecto a estas temáticas, vinculándolas a los derechos humanos.

- Contemplar el peso de las religiones y los tabúes en la invisibilización de estas cuestiones.

- Hablar abiertamente de sexualidad sin eliminar un concepto clave como es el deseo.

- Exponer en clase las opiniones que se tienen sobre estos temas.

- Visionar fragmentos de películas en las que se tratan cuestiones de bullying homofóbico.

- Leer fragmentos de obras literarias en los que aparezcan ideas sobre la sexualidad, sobre el placer y sobre el deseo.

- Desestigmatizar aspectos como la homosexualidad o la transexualidad, incorporándolos a nuestro vocabulario habitual.

- Aclarar que el problema no es la homosexualidad: el problema es la homofobia.

Tras haber expuesto los objetivos generales y secundarios, planteamos como objetivo principal y prioritario la realización de una propuesta de ejercicio en el que se desarrolla una actividad que servirá para combatir el bullying homofóbico de las aulas y de nuestros centros educativos.

(c)) EY-NC-ND 2016, Universitat Politècnica de València

Congreso In-Red (2016) 
La actividad tendrá en cuenta que posteriormente se puede conocer y difundir a través de Museari Museu de l'Imaginari, un museo online que se puede visitar en el website www.museari.com. Museari también dispone de espacio propio en las redes sociales como Facebook https://www.facebook.com/Museari-Museu-de-lImaginari-1050674954942911 o Twitter, así como en la plataforma academia.edu, un repositorio de trabajos científicos universitarios en el que se pueden encontrar las publicaciones sobre diversidad sexual y educación que están difundiendo quienes participan voluntariamente en Museari Museu de l'Imaginari https://independent.academia.edu/museari

Por tanto, uno de los objetivos que pretende la propuesta consiste en difundir aquellos trabajos realizados por el alumnado Magisterio de la Universitat de València dentro del "Proyecto Tolerancia Cero con el Bullying Homofóbico".

\section{Desarrollo de la innovación}

La metodología por proyectos que aplicamos en esta propuesta nos permite realizar un work in progress motivador, de manera que durante las semanas del proceso se van incorporando numerosas novedades que tendrán cabida en el resultado final. No perdamos de vista que el alumnado de Magisterio ha tenido poco contacto anteriormente con las artes, con la educación artística o con los procesos creativos en general. Es por ello que cuando planteamos la propuesta suele apreciarse un cierto malestar en una parte de dicho alumnado. No se sienten seguros a la hora de iniciar un proyecto del que no saben a ciencia cierta hasta dónde puede llegar. Mi frase inicial suele ser: "En estos momentos quien más confía en vosotros soy yo, vuestro profesor. Pero ya veréis como cuando este trabajo se concrete en las propuestas finales, todos y todas estaréis satisfechos con los resultados"

Así pues, resulta necesario animarles y motivarles desde el principio, aunque no tengan muy claro hasta dónde son capaces de llegar. Precisamente en eso consiste elaborar una metodología basada en proyectos: en no saber qué se puede alcanzar con nuestra imaginación y nuestro deseo de innovar.

\subsection{Primeras nociones sobre derechos humanos y diversidad sexual}

Cada vez disponemos de más ejemplos para explicar en clase las cuestiones de la diversidad sexual mediante películas, literatura, videojuegos, fotografía y artes visuales en general. A pesar de que las cuestiones sobre educación artística y diversidad sexual empiezan a tratarse a nivel universitario (Huerta y Alonso-Sanz, 2015), lo cierto es que todavía existen muchos prejuicios al respecto. Se tienden a confundir las temáticas, ya que los medios de comunicación solamente se ocupan de temas escabrosos y de realidades muy conflictivas. Deberíamos contar con una visibilidad reforzada de estas cuestiones en la television y en los medios que habitualmente llegan a un mayor número de usuarios (Eribon, 2014). Pero lo cierto es que no existe ningún motivo o impedimento que explique por qué se sigue invisibilizando la temática LGTB en los centros escolares, en los institutos de secundaria y en las aulas universitarias.

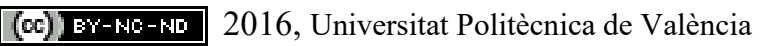


Un documento importante al que puede acceder el alumnado para informarse de manera atractiva, con muchos datos recogidos para contrastarlos, es el informe "Abrazar la diversidad", que se puede consultar en el enlace

http://www.inmujer.gob.es/actualidad/NovedadesNuevas/docs/2015/Abrazar_la_diversidad .pdf

En este importante trabajo de divulgación, su coordinador José Ignacio Pichardo nos presenta las claves de la situación que se está viviendo en los centros educativos respecto a la diversidad sexual. Aquí toman voz el profesorado, el alumnado, los asistentes sociales y psicólogos, los medicos y el personal sanitario, así como responsables politicos y gestores de distintas ideologías y opiniones. Urge tratar las cuestiones valorando la situación de manera objetiva, algo que nos proporcionan este tipo de documentos (Pichardo, 2015).

Aprovechamos las primeras sesiones teóricas para introducir autores y tendencias que conviene conocer. Teniendo en cuenta la importancia que ha adquirido en los últimos meses la cuestión Trans, aconsejamos la lectura de los textos publicados por Miquel Missé y Gerard Coll-Planas (Missé y Coll-Planas, 2011) así como los títulos de Lucas (Raquel) Platero (Platero, 2014) o el recopilatorio coordinado por Jordi Planella (Planella, 2015). Algunas cuestiones referidas a las imágenes en la historia son bien recibidas entre el alumnado, ya que les permiten tantear lo que ha venido ocurriendo con este tipo de temáticas tan invisibilizadas a lo largo de los siglos (Navarro, 2015).

Con estas primeras nociones informativas sobre la realidad LGTB y sus problemáticas se pretende establecer un primer paso hacia la normalización que debería imperar al tratar estas cuestiones, más allá de los prejuicios tradicionales y de los complejos e ignorancia que suelen acompañar el asunto. No podemos permitirnos el lujo de olvidar la cuestión o de dar por sentado que estos temas no tienen importancia. Los derechos humanos son de calado primordial para la formación universitaria de los futuros maestros y maestras. Al explicar y comentar abiertamente sobre aspectos LGTB provocamos un ambiente distendido en el que aquellas personas que anteriormente se habían encontrado con el impedimento de hablar pueden ahora expresarse libremente.

El derecho al libre desarrollo de la personalidad, a una vida digna y libre de violencia, constituye uno de los principales derechos humanos reconocidos internacionalmente (Art. 5, 12, 22 y 26 de la Declaración Universal de los derechos Humanos). El derecho a la educación sin discriminación por orientación sexual o identidad de género se encuentra respaldado por los artículos 2, 28 y 29 de la Convención sobre los Derechos del Niño y en los Principios de Yogyakarta. La discriminación y la exclusión por homofobia y la transfobia son realidades presentes en todas las sociedades, que se reproducen también en los centros educativos (Louis, 2015). No cumplir con las normas de género asignadas culturalmente a hombres y mujeres (Butler, 2006) son algunas de las causas más frecuentes de acoso escolar: motivan desde el insulto y la burla, hasta la exclusión y la violencia física. Por ello conviene no minimizar el problema invisibilizándolo o tratando de justificarlo. La intervención frente al acoso escolar por homofobia o transfobia es una responsabilidad que el personal docente y

(c)) EY-NC-ND 2016, Universitat Politècnica de València

Congreso In-Red (2016) 
todos los miembros de la comunidad educativa deben cumplir y hacer cumplir en el desarrollo de sus tareas, más allá de las creencias o ideologías personales (Pichardo, 2015).

\subsection{Algunos ejemplos destacados que proceden de la creación audiovisual}

Estos últimos meses hemos asistido a un verdadero y sorprendente alud de películas (tanto grandes producciones como obras de realizadores independientes) que han tratado desde diversas perspectivas la cultura LGTB. Desde films que han estado en las nominaciones a los premios Óscar 2016 de la Academia de Hollywood, como Carol (Todd Haynes, 2015) o The Danish Girl (Tom Hooper, 2015), hasta películas mucho más arriesgadas y emotivas como Pride (Matthew Warcus, 2014), Pasolini (Abel Ferrara, 2015), El club (Pablo Larraín, 2015) o la muy recomendable para el público más joven Hoje eu quero voltar sozinho (Daniel Ribeiro, 2014). Cada una relata un modelo diferente de relaciónes personales y sociales. Mientras Carol apuesta por revisar los años cincuenta del siglo pasado a partir de una relación lésbica de mujeres de diferente edad, The Danish Girl nos habla de la primera mujer trans que se sometió a una reasignación de sexo. En la británica Pride asistimos a una recuperación histórica de las reivindicaciones políticas del movimiento LGTB, algo similar a lo que ya consiguieron otros títulos anteriores como Milk (Gus van Sant, 2008) o Dallas Buyers Club (Jean-Marc Vallée, 2013). También recurre a la recuperación de una figura histórica como la de Pier Paolo Pasolini el oscuro e intrigante film de Abel Ferrara, mientras que la chilena $E l$ $c l u b$ apuesta por los abusos cometidos por el clero durante la dictadura de Pinochet. La fresca y sorprendente Hoje eu quero voltar sozinho presenta la realidad de un adolescente ciego que relata en primera persona sus deseos, miedos y frustraciones en el terreno amoroso.

Disponemos, por tanto, de suficiente material cinematográfico como para alentar y documentar al alumnado en su propuesta para el "Proyecto Tolerancia Cero con el Bullying Homofóbico". Podemos analizar las imágenes del cartel con que se nos presenta cada film, para comprobar si responden a las expectativas del alumnado. Habiendo estudiado la temática de la gráfica de las películas (Huerta, 2013), me intereso por la cuestión y paso a explicarles hasta qué punto los mismos elementos dispuestos en un cartel pueden significar una cosa u otra. La persona responsable del diseño, el profesional que se encargará de "vender la imagen" de la película, tiene unas instrucciones asignadas que debe cumplir. Pero lo más interesante de este asunto es que los carteles (al igual que los títulos) son cambiados en cada país, hasta el punto de que una misma producción puede resultar irreconocible si ponemos enfrentados los carteles con los que se ha presentado en Estados Unidos, España, la India, Rusia o Irán, países estos últimos donde, por cierto, esta prohibida cualquier alusión pública a la homosexualidad. 

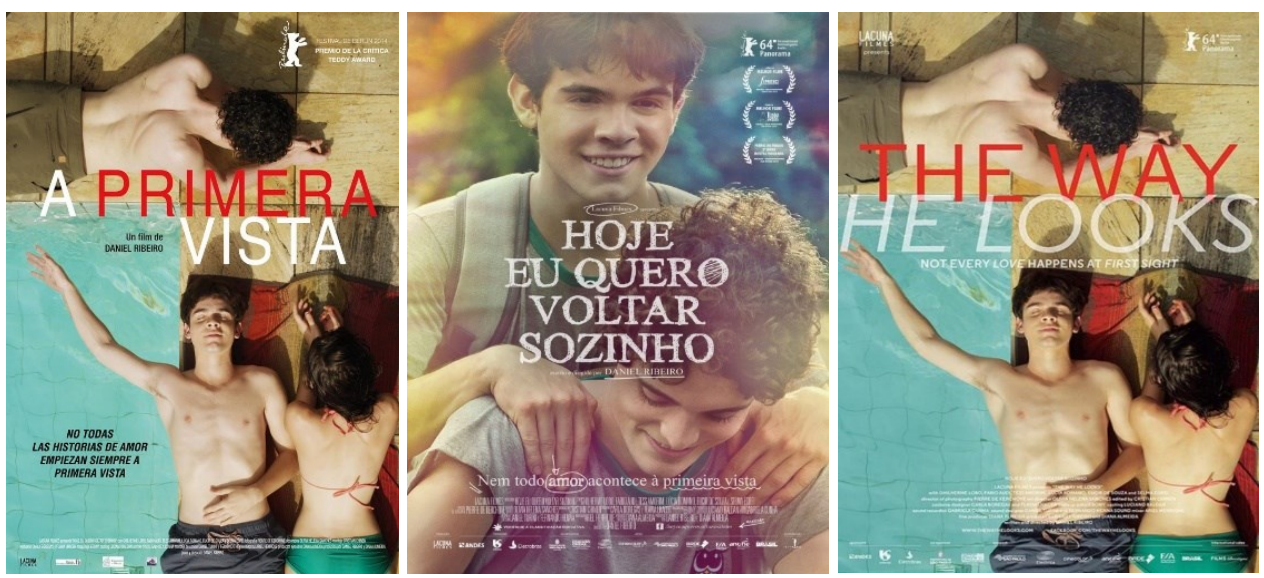

Figs. 1, 2 y 3. Tres versiones del cartel del film brasileño "Hoje eu quero voltar sozinho", para su distribución en España, Brasil y Estados Unidos, respectivamente.

Vemos y comprobamos que no solamente cambia la imagen de la fotografía del cartel, sino que las tipografías son muy distintas, además de haber cambiado completamente el sentido de la frase o la idea a que hace referencia. Observamos que el título original brasileño (en portugués) nos habla de la situación en la que cualquier adolescente se encuentra cuando dice a sus padres "hoy quiero volver solo a casa". Se refiere al momento de necesidad de independencia, de querer "valerse por sí mismo". Pero en ningún momento nos da información sobre la ceguera del personaje principal. Ni tampoco alude a su homosexualidad. En el cartel original brasileño son los dos personajes hombres quienes ocupan todo el terreno gráfico. Al tratarse de dos jóvenes adolescentes, la primera lectura es la de dos amigos jóvenes. En la versión estadounidense (en inglés) ya aparece un personaje femenino en la escena, que por cierto se ha trasladado a una piscina, y es aquí donde la desnudez de los cuerpos entra en acción. La expresión "The Way He Looks", que podríamos traducir como "la dirección que él elige", ya nos acerca a una determinada forma de ser (homosexual, en este caso), idea que se refuerza por el hecho de que la mano del personaje que vemos de cara sube hacia el cuerpo del otro personaje masculino de la imagen. Cuando por fin llegamos a la versión en español, todo ha quedado reducido a un "A primera vista" que solamente encaja con la ironía que podría revelar la discapacidad visual del personaje principal. No tiene la más mínima gracia, ya que se ha perdido cualquier sutileza, que era patente en su versión original. Aunque parece ser que los responsables de traducir al castellano en las distribuidoras españolas siguen en ocasiones una línea estética que nos acercaría más la saga "Torrente" que a las sutilezas de que se goza en otros países. Esto ya viene de lejos, y aprovecho la ocasión para denunciarlo. Ha quedado claro y evidente en la traducción que se ha hecho recientemente del título (y en el cambio estético del cartel) de la última película del actor cómico Sacha Baron Cohen. Su título original The Brothers Grimsby (Louis Leterrier, 2016) ha sido destrozado en todos los sentidos al adjudicarle un más que bochornoso Agente contrainteligente. Y lo peor de todo ello es que el cartel en su versión española resulta irreconocible (y penoso) al ser comparado con el original.

(cc)) BY-NC-ND 2016, Universitat Politècnica de València

Congreso In-Red (2016) 

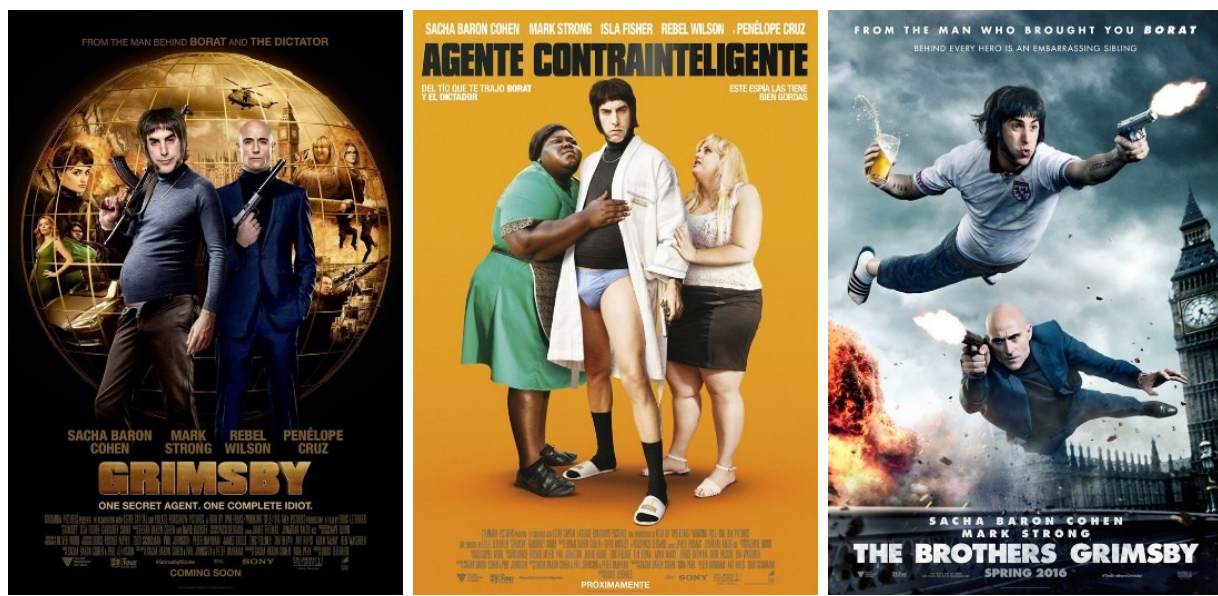

Figs. 4, 5 y 6. Tres versiones del cartel del film anglosajón "Grimsby", para su distribución en Estados Unidos, España y Reino Unido respectivamente.

De nuevo nos quedamos sorprendidos con el cambio de estrategia que siguen los responsables de la distribución española, cuya técnica consiste en banalizar despectivamente todo aspecto interesante o sutil que pudiese haber en el original. Si bien el título original de la película era The Brothers Grimsby, se optó por eliminar la referencia a su parentesco, reforzando así el nombre de la ciudad inglesa, y concretamente de la barriada de Cleethorpes, muy afectada por los recortes sociales y económicos durante los gobiernos conservadores de la era thatcheriana. El club de fútbol al que da nombre (Grimsby Town Foorball Club) tiene mucho sentido en el argumento de la trama del film, en el cual además se mezclan cuestiones referidas a la adopción de uno de los hermanos, y por tanto a las diferencias sociales que les han separado en las últimas décadas. Todos estos suculentos significados quedan reducidos a la ignominia cuando vemos el título traducido al español. Pero lo peor de todo es la imagen con la que se ilustra el grafismo de la versión española.

Si bien en los otros ejemplos habíamos visto destacadas las figuras (algo grotescas pero simpáticas) de los dos hermanos, en el cartel español ha desaparecido esta relación fraterna, y lo que vemos es a un energúmeno en calzoncillos (de nuevo la estética que podríamos asociar a la saga "Torrente") agasajado con caricias por dos mujeres obesas. Lo que elimina totalmente este cartel es la alusión clara a la homosexualidad que derrocha el hermano "agente", tanto en sus gustos como en su trayectoria, a pesar de las maneras bruscas con las que actúa, dentro de su papel como agente secreto. El guión de Sacha Baron Cohen (más allá de la sal gorda con la que condimenta los diferentes momentos del film) contiene una gran sabuiduría, y es lamentable que tengamos que sufrir estas obsesivas transmutaciones y castraciones cuando nos llegan los productos originales, que por mor de dobladores y traductores se convierten en esperpénticas mutaciones de lo que fueron unas originales e innovadoras ideas. Lo cierto es que al transformar los significados originales suele haber una obsesiva fijación por eliminar la parte sensual, el deseo o la diversidad sexual, lo cual nos retrotrae a una forma de funcionar mucho más propia de la época de la inquisición o de los censores franquistas. 


\subsection{Artistas que defienden la diversidad sexual}

En el museo online Museari, Museu de l'Imaginari trabajamos por normalizar la situación en lo referido a los derechos de las personas y los colectivos LGTB. Lo hacemos desde las artes, desde la educación artística y desde la historia. Somos activistas en la defensa de los derechos humanos. Nos esforzamos por impulsar logros desde los cuales se puedan aumentar las libertades y opciones, sumando fuerzas, atendiendo a la riqueza de la diversidad. Asuntos legales como el matrimonio igualitario o los derechos de las personas trans están logrando que se superen los miedos y las injusticias que habían padecido hasta hace bien poco las personas que no encajaban en las normas heteronormativas y patriarcales con las cuales se nos adoctrina y enmarca desde prácticamente el día en que nacemos (García, 2015). Romper con estos marcos de género establecidos supone romper las barreras de la corrección social, política y cultural. Es algo que mucha gente no está dispuesta a aceptar, y que desde las religiones monoteístas se combate con ataques de todo tipo. Pero lo cierto es que se están dando pasos en positivo, ya que el movimiento LGTB es de carácter internacional y ha demostrado ser capaz de enfrentarse a momentos mucho peores que el actual. De todos modos, no conviene aletargarse ni confiar en que todo lo logrado perdurará eternamente. Los derechos humanos hay que conquistarlos cada día, y en esa lucha nos encontramos muchísimas personas que creemos en la humanidad y en la capacidad de superar las peores situaciones.

Museari, Museu de l'Imaginari se creó para ofrecer información y para difundir y defender los derechos de las personas y los colectivos LGTB. Desde su creación en julio de 2015 hemos inaugurado una exposición cada mes. Artistas de varios países han participado en esta aventura artística que permite reforzar los avances que venimos logrando en todo aquello referido a la diversidad LGTB. Un matrimonio de dos hombres es motivo de alegría y satisfacción. El fotógrafo Xavier Mollà supo recoger en sus instantáneas las emociones del momento.
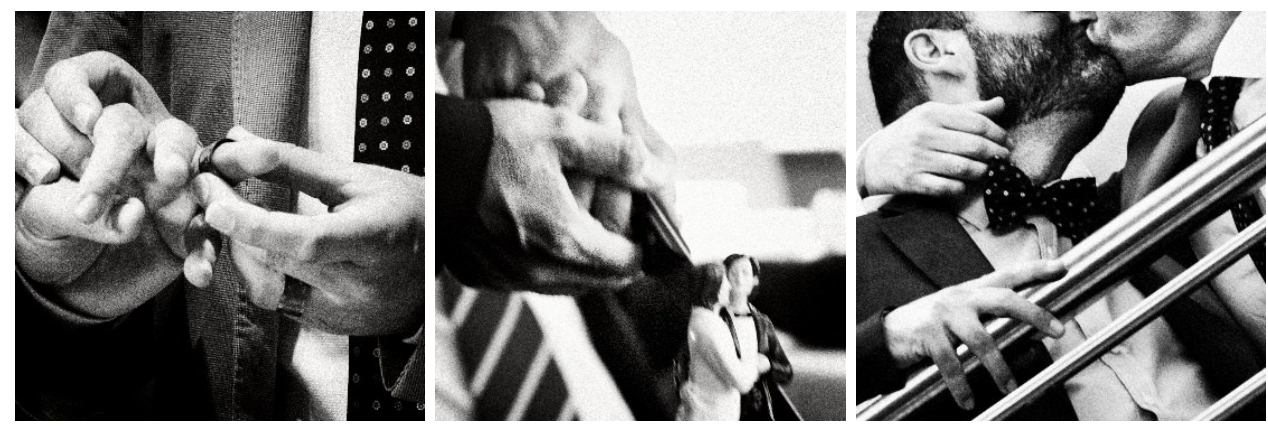

Figs. 7, 8 y 9. Fotografias del artista Xavier Mollà de la serie "Mans d'Estimar", seleccionadas para su exposición en "Museari, Museu de l'Imaginari".

Cuando el artista Xavier Mollà retrata a esta pareja de recién casados para confeccionar un álbum de fotos de boda, sabe que no está fotografiando a una pareja convenciona de recién casados. Ni los novios son jóvenes veinteañeros (la tradición prescribe que deben ser jóvenes quienes se casan) ni tampoco son el novio y la novia tradicionales (con sus respectivos roles machistas convencionales ya asignados). Se trata de dos hombres que han decidido

\section{(cc) EY-NC-ND 2016, Universitat Politècnica de València}

Congreso In-Red (2016) 
formalizar su relación sentimental mediante un acto público. Este posicionamiento dista mucho del tradicional "vale, sabemos que estáis junto, pero mejor lo lleváis en secreto, y así todos tranquilos". Esta situación hipócrita y degradante ha sido expresada en numerosos relatos literarios, incluso en algunos que han sido llevados al cine (Bayly, 2003). Todo esto conviene relatarlo a los futuros y futuras docentes, ya que el posicionamiento del profesor en casos como este resultará muy pregnante para el alumnado de Magisterio.
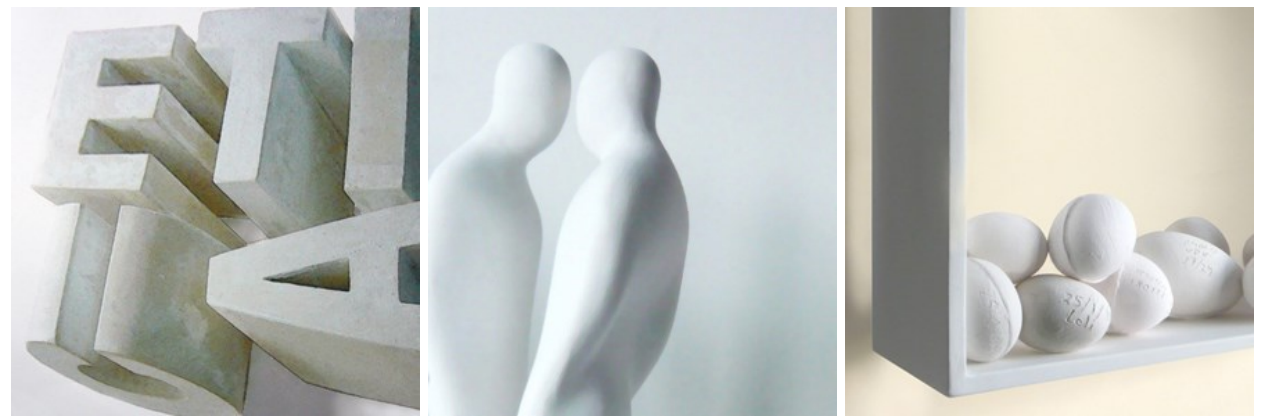

Figs. 10, 11 y 12. Piezas escultóricas del artista Adolfo Siurana de la serie "Mans d'Estimar”, seleccionadas para su exposición en "Museari, Museu de l'Imaginari".

Adolfo Siurana es escultor, formado en España y Alemania. Sus obras nos descubren un modo peculiar de análisis de la realidad. El cuerpo humano es uno de sus temas recurrentes, pero dentro de sus planteamientos domina la idea de la fragilidad y al mismo tiempo la fuerza de los materiales. En sus piezas trabaja con cerámica, y son conocidos sus trabajos desarrollados con cáscara de huevos, un elemento frágil y robusto al mismo tiempo. Esta idea de contraste entre los que se supone la fuerza y la debilidad es la que destaca en su exposición "Hombrías" presentada en Museari. Reproducimos aquí tres de las piezas expuestas. La figura 10 corresponde a la obra Jabones Aurora, compuesta por cinco piezas realizadas con jabón, y que al juntarlas nos permiten leer la palabra "Ética". Toda una declaración de principios. La figura 11, que se titula "Hombrías" (al igual que la exposición en su conjunto) representa a dos hombres que se miran, que están cerca, que casi se tocan, que deciden cosas juntos. La figura 12 titulada "Marcos educativos" hace referencia justamente al encajonamiento desde el cual se nos adiestra para que seamos fieles portadores de las normas heteropatriarcales en las que nacimos y hemos crecido. Observamos, de nuevo, un planteamiento crítico y reflexivo que cuestiona los marcos de género.

A partir de los artistas que exponen en Museari, se plantean en clase otros referentes que también han luchado por visibilizar la realidad LGTB, refiriéndonos a personajes tan conocidos dentro del panorama artístico internacional como David Hockney, Gilbert \& George, Jasper Johns, Andy Warhol, Cy Twombly, Robert Rauschenberg, Frida Kahlo, Nora Ancarola, Pepe Miralles, y tantos otros ejemplos de personas creativas que han realizado y siguen realizando piezas combativas con las que defender los derechos de la diversidad sexual, que son, al fin y al cabo, derechos humanos.

Cabe incidir en que durante esta primera fase informativa y formativa, el alumnado sigue sin confiar abiertamente en sus propias posibilidades de creación. No se sienten "artistas", lo 
cual dificulta la posibilidad de abrirse a experiencias de creación. Es en el momento en que comprueban que sus imágenes también transmiten sentimientos y deseos, cuando empiezan a ser conscientes de sus potenciales. Tal y como se demuestra al revisar las prácticas artísticas de los países iberoamericanos, la desobediencia es una de las claves del atractivo de dicho posicionamiento (Aliaga y Cortés, 2014), algo que Luis Camnitzer también ha puesto de relieve en sus escritos y obras de arte (Camnitzer, 2009), y que denunció Michel Foucault en muchas de sus reflexiones (Foucault, 1998 y 2009).

\section{Resultados}

Tras haber dedicado varias sesiones de clase a revisar obras de arte, artistas, películas, textos literarios, anuncios televisivos, webs, blogs y otras modalidades comunicativas en las que encontramos ejemplos valiosos para activar la defensa de los derechos humanos, pasamos a la fase de concreción de sus propuestas. El trabajo en el taller requiere una atención constante por parte del profesor, algo que no resulta fácil cuando se trata de grupos de alumnado que suman unas 50 personas por clase. La revisión de las propuestas se hace individualmente. Por norma habitual no disponemos de tiempo suficiente en el horario lectivo de las clases, y es por ello que las tutorías suelen aprovecharse para terminar de cerrar las propuestas.

Aquí cabe implicar a las asociaciones que están desarrollando proyectos innovadores que suponen avances sociales, como puedan ser las plataformas del colectivo Lambda $<$ http://www.lambdavalencia.org/es $>$, la asociación Chrysallis de familias de menores transexuales <http://chrysallis.org.es $>$, la Federación Estatal de grupos LGTB $<$ http://www.felgtb.org $>$, o incluso otros museos e instituciones que también defienden la diversidad sexual en otros tantos lugares del mundo, como el de Sao Paulo en Brasil $<$ http://www.mds.org.br $>$. Todas estas referencias, y otras que aporta el propio alumnado al indagar en Internet, consiguen animar el taller para concretar sus propuestas.

Los resultados son siempre atractivos, y responden a unos modelos estéticos y gráficos muy acordes con la edad del alumnado, que ronda los 21 años. En algunos casos se presentan reflexiones vinculadas a videojuegos o webs interactivas que les gustan. En la mayoría de los casos se trabaja con fotografias y videos realizados por el propio alumnado. El montaje y postproducció de los videos es una de las soluciones mayoritarias. Les gusta el trabajo titulado Álex en Barcelona realizado por las alumnas Nataly Prada y Laura Ortiz del «Master de Artes Visuales y Educación: Un Enfoque Construccionista», documento que puede consultarse en YouTube en abierto.

Un porcentaje elevado de las propuestas incluyen juegos pensados para el aula, separando por grupos al alumnado, estableciendo criterios de participación, invitando a quienes participan a establecer un rol. La alumna JBM lo expone así: «Mostraremos al alumnado de segundo de primaria una imagen en la que se ven diferentes tipos de familias: monoparentales, homosexuales y heterosexuales. A continuación hablaremos de la variedad familiar, comentando la imagen. Por grupos iniciaremos un debate para exponer sus opiniones, mientras el docente observa si el clima es de tolerancia y respeto, para ver los aspectos que debe trabajar en la siguiente sesión". La alumna CGE insiste en las marcas de

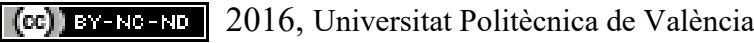

Congreso In-Red (2016) 
género al plantear: "Para la actividad utilizamos dos fotografías de bebés, en las que no se aprecia si es niño o niña. Al bebé de la imagen 1 el maestro le da un nombre de chico y al de la otra imagen un nombre de chica. Organizamos la clase en grupos y asignamos cada fotografías a un grupo. Los niños/as tendrán que escribir una historia sobre el bebé que les ha sido asignado, contestando a una serie de preguntas: ¿cómo será su forma de ser, su vida, que estudiará, cuál será su trabajo, cuáles serán sus hobbies?. Cuando los grupos hayan redactado las historias se leen en voz alta y entre todos se buscan similitudes o contrastes entre las historias del bebé niño y de la niña. Cuando finalizan las lecturas, el maestro descubre a la clase que el bebé de ambas imágenes es el mismo, y les explica cómo por el hecho de la asignación de género se espera socialmente un comportamiento y unos logros diferentes".

Comprobamos al revisar estos trabajos que la capacidad creativa del alumnado siempre está por encima de las previsiones que tenían inicialmente. El proceso que hemos seguido ha contado también con la recuperación de materiales de diversas publicaciones vinculadas a la investigación en educación y en artes visuales. Les animamos a buscar referencias y artículos en las webs de revistas como Arteterapia. Papeles de arteterapia y educación artística para la inclusión social, Arte, Individuo y Sociedad, EARI Educación Artística Revista de Investigación,@TIC,Pulso Revista de Educación,International Journal of Art and Design Education, International Journal of Education Through Art, Temps d'Educació, y otros documentos que les sirven para fmiliarizarse con las artes y la educación artística. A medida que avanza su trabajo se alimentan de ideas que van barajándose en el work in progress que supone el "Proyecto Tolerancia Cero con el Bullying Homofóbico". Todos y todas coinciden en valorar positivamente la experiencia, algo que les ha servido para concienciarse de la necesidad de atajar esta lacra social que es la homofobia, o bien un problema tan grave como el acoso escolar, y de manera especial el bullying homofóbico, algo que responde a prejuicios machistas propios de otras épocas, y que debe resituarse en una sociedad democrática como la nuestra.

El uso de imágenes en sus trabajos constituye uno de los logros más novedosos, ya que establecen criterios de alfabetidad visual en sus propuestas. Las reflexiones a partir del estudio de películas, carteles, obras de arte, la web de un museo y elementos visuales en general, fortalecen el conocimiento de la imagen como discurso. La posibilidad de difundir sus trabajos como actividades mediante un museo online les motiva y les seduce como reto.

\section{Conclusiones}

Coincidimos con Imanol Agirre en que la experiencia del arte debe convertirse en un elemento vivencial de primer orden (Agirre, 2000). Lo cierto es que la educación artística, y quienes nos encargamos de impartirla en las aulas universitarias, tenemos un verdadero compromiso con la sociedad y con la defensa de los derechos humanos, algo que debe demostrarse con las acciones oportunas (Huerta, 2014). El proceso es lento, pero debe ser constante, tal y como demuestran algunos educadores que llevan años trabajando en esta línea de respeto y visibilización de los colectivos LGTB (Parral, 2014). Los buenos resultados del "Proyecto Tolerancia Cero con el Bullying Homofóbico" evidencian que tratar estas 
temáticas en el aula sirve para visibilizar una realidad que en demasiadas ocasiones había estado oculta a causa de prejuicios y tabúes (Motta, 2013). El uso de dispositivos digitales, como es el caso de Museari, Museu de l'Imaginari, activa mecanismos de motivación entre el alumnado, ya que les permite posteriormente difundir sus propuestas y compartirlas con otros compañeros y con docentes en ejercicio. A los futuros maestros y maestras conviene ofrecerles posibilidades de intervenir con la mirada puesta en el cambio social, activando dinámicas colaborativas y participativas.

\section{Referencias}

AgIRRE, I. (2000). Teorías y prácticas en educación artística. Ideas para una revisión pragmatista de la experiencia estética. Pamplona: UPN.

Aliaga, J. V. y CoRTÉs, J. M. (2014). Desobediencias. Cuerpos disidentes y espacios subvertidos en el arte en América latina y España: 1960-2010. Barcelona: Egales.

BAYLY, J. (2003) No se lo digas a nadie. Barcelona: Seix Barral.

ButLer, J. (2006). Deshacer el género. Barcelona: Paidós.

CAMNITZER, L. (2009). Didáctica de la liberación: Arte conceptualista latinoamericano. Murcia: Cendeac.

ERIBON, D. (2014). La societé comme verdict. Classes, identités, trajectoires. Paris: Flammarion.

Foucault, M. (1998). Historia de la sexualidad II: el uso de los placeres. México: Siglo XXI Editores.

Foucault, M. (2009). Viglar y castigar. Nacimiento de la prisión. México: Siglo XXI Editores.

GARCÍA, U. A. (2015). “Un marco teórico inclusivo. Teoría de los marcos de género” en EARI Educación Artística Revista de Investigación, 6, pp. 84-98.

HUERTA, R. (2013). La tipografía en el cine: análisis de cabeceras y créditos de películas como estrategia educativa desde la cultura visual, Archivo de Arte Valenciano, 94, 351-366.

Huerta, R. (2014). La educación artística como motor de cambio social, Cuadernos de Pedagogía, 449, 48-50.

Huerta, R. y Alonso-SAnZ, A. (eds.) (2015). Educación artística y diversidad sexual. Valencia: PUV.

LouIs, E. (2015) Para acabar con Eddy Bellegueule. Barcelona: Salamandra.

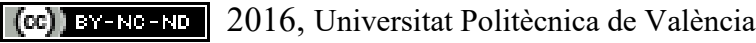

Congreso In-Red (2016) 
Formación de docentes y defensa de los derechos humanos mediante actividades educativas en museari.com

Missé, M. Y Coll-Planas, G. (2011). El género desordenado. Críticas en torno a la patologización de la transexualidad. Barcelona: Egales.

MotтA, C. (2013) (Im)partial (im)possibilities, e-flux, 44, 1-9.

NAVARro, G. (2015). "Las imágenes de la diversidad sexual en la Edad Media” en R. Huerta y A. Alonso-Sanz (eds.) Educación artística y diversidad sexual. Valencia: PUV, pp. 61-78. PARRAL, V. (2014). Quiero ser Queer-ARTecno-CREATIV@: Ciborgs, prótesis y drags en la ESO, Cuadernos de Pedagogía, 449, 61-63.

PICHARDO, J. I., coord. (2015). Abrazar la diversidad: propuestas para una educación libre de acoso homofóbico y transfóbico. Madrid: Instituto de la Mujer y para la Igualdad de Oportunidades.

Planella, J., PIÉ, A., coords. (2015). Políticas, prácticas y pedagogías TRANS. Barcelona: Editorial UOC.

Platero, R. (L.) (2014). Transexualidades. Acompañamiento, factores de salud y recursos educativos. Barcelona: Bellaterra.

(cc) EY-NC-ND 2016, Universitat Politècnica de València Congreso IN-RED (2016) 